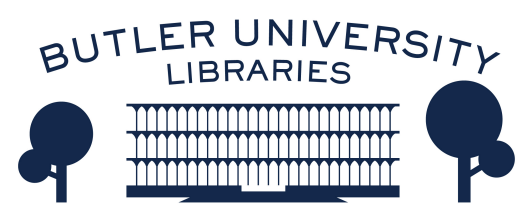

Journal of Hindu-Christian Studies

January 2004

\title{
How the Numbers Matter: Demographics and the Future of Hindu- Christian Dialogue
}

Francis X. Clooney

Follow this and additional works at: https://digitalcommons.butler.edu/jhcs

Part of the Religion Commons

\section{Recommended Citation}

Clooney, Francis X. (2004) "How the Numbers Matter: Demographics and the Future of Hindu-Christian Dialogue," Journal of Hindu-Christian Studies: Vol. 17, Article 6.

Available at: https://doi.org/10.7825/2164-6279.1315

The Journal of Hindu-Christian Studies is a publication of the Society for Hindu-Christian Studies. The digital version is made available by Digital Commons @ Butler University. For questions about the Journal or the Society, please contact cbauman@butler.edu. For more information about Digital Commons @ Butler University, please contact digitalscholarship@butler.edu. 


\title{
How the Numbers Matter: Demographics and the Future of Hindu-Christian Dialogue
}

\author{
Francis X. Clooney, S.J. \\ Boston College
}

Religious Demography of India. A. P. Joshi, M. D. Srinivas, and J. K. Bajaj. Chennai: Centre for Policy Studies, 2003. xxii +358 pp.

IN Religious Demography of India, Bajaj, Joshi, and Srinivas analyze Indian census data from 1871 to 1991 , in order to assess the shifts in demography in religious identity in India and on that basis make predictions about the future. They look closely into the data regarding the various states of India, and even the individual districts of those states. The book, coming in two parts, invites readers to study the data for themselves: the first 175 pages offer an analysis of census data, but pp. 179-346 are comprised entirely of tables reporting data, thus enabling readers to make up their own minds.

Throughout, "India" refers to Pakistan, Bangladesh, and India itself, here known as "the Indian union." The book proposes a kind of homogeneous native tradition comprised of "native religionists;" this group includes all the various Hindu traditions but also some other traditions too. As critics have noted (see below), the book is both overly generous and at the same time stingy: "Indian religionists" include Hindus, Buddhists, Jains, Sikhs, and also, strikingly, Parsis and Jews, but none of the Christian communities long and peacefully established in India, such as the Syriac Christians of Kerala, or the old Catholic communities of Tamil Nadu. Indeed, the Indian religionists are contrasted with the two aggressive religions from the West, Islam and Christianity.

In the first part of this essay I comment directly on the book and reactions to it; in the second, I survey a few of the reactions to it in India; in the third, I sketch the possibilities of a wider, more integral study of the religious significance of demographic changes; in the fourth, I suggest how attention to it can affect Hindu-Christian studies. First, though, an admission: two of the authors of Religious Demography of India, M. D. Srinivas and J. K. Bajaj, are friends of mine whom I am always happy to visit when in Chennai. I begin with respect for their integrity and seriousness about their work. I have also admired the contemporary analyses written and published by their Centre for Policy Studies in Chennai: Dharampal's Bharatiya Chitta Manas and Kala (tr. by J. K. Bajaj; see the discussion of this book in the Hindu-Christian Studies Bulletin in 1995), their monograph on food, food production, and hospitality, Annam Bahu Kurvita, and a timely edited volume, Ayodhya and the Future of India (1993, edited by J. K. Bajaj). In my mind, these

Francis X. Clooney, S.J., is Professor of Comparative Theology at Boston College. During 2002-2004 he was Visiting Academic Director at the Oxford Centre for Hindu Studies. His most recent book, Divine Mother, Blessed Mother: Hindu Goddesses and the Virgin Mary is forthcoming (Oxford University Press 2004). 
books demonstrate the authors' concern for India's religious identity, studied in the bright and harsh light of contemporary issues. I therefore approached this new book with a favorable attitude and willingness to take their research seriously, and in fact found Religious Demography a fascinating if not entirely adequate basis for a fresh assessment of "interreligious dialogue on the ground" in South Asia today. Yet I also write from Boston, and concede that regarding this book, like other publications from India, I may be missing some of the contextual factors that mark Indian readings of the book.

I.

At the book's start, the authors soberly assess the situation, stating their presupposition and conclusion:

India, on the whole, has resisted Christianization; proportion of Christians in India remains around 2 percent. And, India has not succumbed to the expansion of Islam like some countries of Africa." (p. xxii). But Indian experience of the twentieth century has not been nearly as robust as that of China, where "not only the proportion but also the absolute number of Muslims... has declined, and Christianity has failed to find any foothold. (p. xxii)

At the book's end, the authors' perspective is broadened toward a global overview:

Thus, seen in the perspective of the changing religious demography of the world during the twentieth century, [the] Indian situation does not seem too alarming. Christianity and Islam have both made substantial gains in the world. But it is Africa and some relatively smaller countries in Asia that have experienced the impact of growth of these religions the most. Africa has lost its Native Religionist moorings during the twentieth century. And in Asia, countries like Indonesia and South Korea have seen their religious complexion change fairly thoroughly. On the other hand, an ancient civilization like that of China has countenanced no change in its religious profile, nor have the relatively more recent civilizational religions of the world like West Asia, North Africa and Europe swayed from their adopted faiths. (pp. 174-175)

Partition and other factors have led to an erosion of the Indian religions, yet there is hope for the future: "[M]uch of the country has remained largely immune to the advance of Christianity or Islam. Indian Religionists have maintained a dominant presence in almost all the northwestern, western, central and southern parts of the Indian Union... In this vast region, Indian Religionists have shown great vitality; any tendency towards significant erosion of their share in any pocket of this region has often been swiftly neutralized." (p. 175) Yet concern is still warranted: "Such vitality, however, has not helped [Indian religionists] in defending their presence on the borders of the country where the efforts of the society, to be effective, necessarily need the vigilance and support of a state committed to protecting and preserving the civilizational identity, pride and genius of the nation. We have so far failed to fashion such a state for ourselves." (p. 175)

The tone of nervousness about the proximity of one's others is reflected in the names of the chapters: "states where Indian religionists dominate," "states where Indian religionists are under pressure," and "states where Indian religionists are turning a minority." It is as if Samuel Huntington's hypertense Clash of Civilizations was on the 
bookshelf right next to the volumes of census data.

Describing interreligious prospects on the basis of census data inevitably leads to oversimplification, since the relationship among religions is read in terms of ever more glaring numbers, while various less easily quantified phenomena are left out of consideration. Caste is left out, for instance, as are other social, political and cultural factors that might affect how religious people change their identities or fashion identities that cut across religious divides. Change occurs and is counted; religions are aggressive or moderate or resistant; but the human persons who make choices shaping these changes are never mentioned. Beyond parents deciding how large a family to produce, presumably communities are comprised of agents able to decide how communities should respond and act in the fact of similar decisions made by people in other traditions. The identity of the agents of religious change and their motives as well require deeper investigation, even if we can also say that there is no one entirely in charge of the religious changes occurring today. There are religious changes, and attention must be given to the agents of that change - missionaries and Dalits, the ultraorthodox and the Mumbai elite, the politicians and the religious reformers who surely have their own plans and their own ways of reading the data. Even the word "conversion" appears not to occur in the book (which has no subject index), even though this key phenomenon - seeking to convert others, choosing to convert - must be closely connected to the trends that presumably disturb the authors.

The analytic chapter concluding Part One of the book borrows data from the World Christian Encyclopedia to put those findings into the context of the wider global pattern of religious demographic changes. Here the authors again simplify the demographic portrait by including among the majority group in each part of the world the "non-religionists" and "atheists" listed in the areas. As a result, the areas of the world are simplified into religious blocks belonging to one religion or another, and the scenario is set for imagining a stark and too clear division between civilizations (perhaps) in (inevitable) clash, or at least competition, with one another. Again, Huntington seems to be in the neighborhood.

\section{II.}

Religious Demography received a great deal of attention in India after its release, in part because it addresses very sensitive issues related to India's religious identity and the future of Hinduism. It was also introduced at a high profile conference in Delhi in October 2003, where L. K. Advani, Deputy Prime Minister, released the book. Mr. Advani also wrote a laudatory foreword, in which he praises it as a guide to the "informed judgments" Indian will have to make about "the strategic pressures India is likely to face. within its neighborhood in the near future." (p. xv) Some reviews praise the book's conscientious use of detail, its eschewal of heated rhetoric, and its sober assessment of a crucial topic. It is valued by many as a work that will remain an essential reference for decades to come.

But Religious Demography has also been severely criticized. The authors are charged with drawing selectively on the voluminous census data, consulting only the religious data and thus oversimplifying the issues. They are also accused of a clumsy and amateur use of statistics, though rarely do the critics explain how statisticians should interpret the data. The book is accused of idealizing an ancient and homogenous Indian past, in part by its odd and problematic categories. Indeed, it is odd that all Jews and all Parsis counted as "Indian religionists" while all Christians and all Muslims are denied this status, portrayed instead as members of aggressive and alien religious communities. 
Some criticisms cut deeply. In The Telegraph (Calcutta, July 10, 2003), Partha Chatterjee calls the volume "shockingly crude" in its underlying "social science theory." Without much ado she dismisses the notion of an ancient "homogenous religious civilization" and in a shorthand theology asserts that the postulation of a timeless sanatana dharma "makes nonsense of all accumulated textual, historical and anthropological scholarship on Indian religions." So too, she terms crude the division of the world into Islamic, Christian, and native religions: "[the authors"] understanding of religion and religious communities is so blissfully ignorant of all social science that one can only attribute it to the intellectual innocence of former physical scientists." In The Week (July 27 2003) B. G. Verghese links Religious Demography to the divisive views of Savarkar, Hedgewar, and Golwalkar, and reads it as favoring a cultural nationalism that in fact has "little reverence for true faith and tradition," however these might be defined. The authors, he says, see India's pluralism and diversity as "a cancer that must be contained if not eradicated." $\mathrm{He}$ suggests that its claims rely on a "bogus sociology" which oversimplifies the "Indian religions" and conceals the underlying tensions within Hinduism, between Hindus and Buddhists and Jains, and along caste lines. The book's call for a national culture is tantamount to an appeal for "cultural sameness" bludgeoned into existence by "sundry cavemen." In People's Democracy (September 28, 2003), Nalini Taneja rails against this "fraudulent study" as a "demonizing demography" pretending to be social science, while in fact being nothing but a government subsidized justification for "ethnic cleansing." The book, in Teneja's view, avoids engaging the problem of defining Hinduism and conjures up a pure, simple Hindu past — and doing all this for the sake of encouraging (as the dust jacket puts it) "the task of nation building," "with an abiding passion." The book is backward looking, out of touch, and dangerous; perhaps, but Taneja is no more forthcoming with proof of her charges or indications of a better way to read the statistics.

These warnings are at least a bit overheated, and they are perhaps aimed really at the Hindu right wing the book is taken to symbolize. The effect, though, is that such reviewers seem to absolve themselves of addressing the specific issues raised by the book. While. Religious Demography might be used by paranoid and vicious elements in Indian society, it need not be inextricably bound to the far right. More trenchant and developed criticisms are to be found at the South Asian Citizen Web, www.sacw.net/2002/daval04072003.html, where John Dayal, in an essay subtly entitled, "Lies, Half Truths and Statistics," offers a lengthy critique of the book, disputing almost every interpretation. His analysis, too detailed to rehearse here, emphasizes mainly that the book is alarmist, prone to read data in an unnecessarily dour fashion, seeing decline and threats where there are none. I am not convinced that Dayal has succeeded in demolishing the authors' main points, but his critique is a valuable companion to the book.

Whatever their skills in statistical analysis, I see no evidence that the authors are trying to obfuscate matters or promote hysteria without discussion. Even the book's oddities - Jews and Parsis as Indian religionists, little nuance regarding Hindu traditions or caste, etc. - are so manifestly evident and at the forefront, unconcealed, that it is hard to charge the authors with doing anything other than what they claim to be doing: putting the statistics before the reader because, in their view, the data raise concerns about the future. Perhaps others can interpret the data better, and it will be for the better were they to undertake an exhaustive study of the census data and offer their own, better prognosis.

III. 
In fact, religious identities are changing constantly, and our authors are simply joining other observers of the hastening pace of religious demographic shifts. In his The Next Christendom: The Coming of Global Christianity (Oxford University Press, 2002), Philip Jenkins reminds us of a global shift in the nature of Christianity. He too is cautious but insistent about the importance of demographics: "Projecting demographic changes as far ahead as fifty years in the future seems like a risky venture... Yet the process of Christian expansion outside Europe and the West does seem inevitable, and the picture offered here is based solidly on current trends, religious and demographic. In this instance, the foolishness seems justified." (p. 79) And Jenkins too sees a dramatic demographic shift under way:

One central fact in the changing religious picture is a massive relative decline in the proportion of the world's people who live in the traditionally advanced nations. If we combine the figures for Europe, North America, and the lands of the former Soviet Union, then in 1900 , these Northern regions accounted for 32 percent of the world population. Viewed over the span of world history, that may have been an untypically large proportion, which, reflected the explosive demographic growth of the industrial revolution years. Over the course of the twentieth century, matters reverted to what was likely a more typical preindustrial norm, as the proportion of peoples living in the advanced nations fell, slowly at first, but then more dramatically. By 1950 , the share had fallen a little to 29 percent, but the rate of contraction then accelerated, to 25 percent in 1970, and around 18 percent by 2000 . By 2050 , the figure should be around 10 or 12 percent.
Relative growth rates in the South have been just as impressive. Africa and Latin America combined made up only 13 percent of the world's people in 1900, but that figure has now grown to 21 percent. Every indication suggests that the rate of change is accelerating. By 2050, Africa and Latin America will probably be home to 29 percent of the world's people. In. 1900, "Northerners" outnumbered these "Southerners" by about 2.5 to one; by 2050 , the proportions will be almost exactly reversed. Overall, global population stands at 6 billion today, and should reach 9 billion around 2050 , but that increase will not be equitably distributed around the globe. Southern nations are growing very rapidly, while their Northern neighbors are relatively static." (pp. 79-80)

Jenkins also takes a step that the authors of Religious Demography do not; he reminds us that the shift is not just a matter of an unchanging Christianity experiencing movement, but of the arising of a newly configured dominant Christianity:

The types of Christianity that have thrived most successfully in the global South have been very different from what many Europeans and North Americans consider mainstream. These models have been far more enthusiastic, much more centrally concerned with the immediate workings of the supernatural, through prophecy, visions, ecstatic utterances, and healing... Nor is this question of authenticity just a matter of academic interest. If in fact the bulk of the Christian population is going to be living in Africa, Asia, or Latin America, then practices that now prevail in those areas will become 
How the Numbers Matter: Demographics and the Future of Hindu-Christian Dialogue 17

ever more common across the globe. This is especially likely when those distinctive religious patterns are transplanted northward, either by migration, or by actual missions to the old imperial powers, to what were once the core nations of world Christianity." (pp. 107-108)

If we see that similar shifts are occurring in other religions too - think of the current self-scrutiny occurring among Muslims globally (see for instance, Lawrence Rosen, The Culture of Islam: Changing Aspects of Contemporary Muslim Life, University of Chicago, 2002), or the changing face of Buddhism (see for instance, James Coleman,

The New Buddhism: The Western Transformation of an Ancient Tradition, Oxford University Press, 2001) - then the "we" of global religiosity too is changing more dramatically, and not just in numbers. Tracking the numbers, without exploring more qualitative issues, is only a small part of a larger and even more interesting story.

In other words, shifting demographics indicate also a shift in how religious identities will be understood and felt in the next centuries. Religious Demography would have been a stronger book has its authors explored the context of their numbers, and been more venturesome in their descriptions of the possible substantive changes in Hinduism as the religion wanes in some areas and grows in others. Cannot we not imagine a global Hinduism that is changing in broader ways that are irreducible to the valid but limited task of counting Hindus in the districts and states of India?

\section{IV.}

To this reviewer, neither a statistician nor a social scientist, Religious Demography succeeds in bringing to the forefront a topic that requires discussion. It raises urgent questions, hard to ignore, as to the domain and climate in which dialogue occurs. We would be mistaken to avoid its questions simply on the grounds that the same statistics bear further and more nuanced readings; the authors have done the service of making it possible to argue about the meaning of the changing numbers. It is evident that India is changing, and it is not a sure thing that Hindu traditions will remain in the majority in the centuries to come. Were I a Hindu, I would be thinking hard about Hindu identity and its future in a world where Christians and Muslims both have devoted much energy to the conversion of members of other religions.

Indeed, Religious Demography seems to tap successfully into real concerns Indian Hindus have about the future of their religion and culture and nation; even the harsh criticisms of the book suggest that sore points have been touched. It does so with a sober array of statistics which, however interpreted, reminds us that change is occurring and change matters. It accentuates, if not aggravates, a more urgent situation in which a more urgent confessional accounting is required. That the book has this value and deserves our attention does not do away with the legitimate concerns underlying it; but it does. force us to reflect on how demographics mark . necessarily deeper theological concerns about which the authors might say more.

The book is so informative that it can confuse by its numbers and push timid readers back into generalities in favor of or against the book. But the matters have to become more complex; to understand what is occurring today requires a shift to a level of more complex social and religious. analysis wherein issues like caste cannot be left out or finessed by broad categorizations that downplay divisions and highlight commonalities; it requires a religious angle, as religious intellectuals are required to respond to a real life situation where the demographics give way to some deeper consideration of how complex religious identities resist counting, and elude the simplifications of demographics. Dividing 
the world in religious blocks aids us in formulating a simple picture, but much of human experience has to do with blurring such boundaries, as people in countries like India or the United States become increasingly disposed to borrow from other traditions. What it means to be Hindu or Muslim or Christian is not decided by historians or sociologists, but by intelligent insiders to traditions who present their ideas in ways that are at least open to conversation with outsiders willing to listen and speak.

Statistics on religion require a theological response if they are to be understood properly; it is not for a statistician or a government employee to define quantitatively what Hinduism is, or what Christianity is. The clumsiness in the book in defining "Indian religionists" is due in large part to the decision of the authors not to engage the larger, reflective questions. Eventually, believers need to be called upon to explain the relationship of the essentials of their traditions to changes marked by demography. The ecology of religious equilibrium and interchange cannot be assessed merely by numbers, and there needs to be the involvement of believers willing to discuss what the numbers mean. It will not work to explain changes only at a level where change is due to an international or governmental strategy. To think more deeply about what Christianity or Islam or Hinduism is would upset the count, and make it difficult to state simply what exactly the census was counting. To fall back on an old phrase: the better census would have to be one in which believers are allowed to stand up and be counted.

This leads me to my final reflection on how Religious Demography might be useful in transforming our negotiation of the Hindu-Christian relationship, including scholarly exchange. Certainly, the book provides a distinctive context for HinduChristian studies. It reminds us of larger patterns of religious demographics that inevitably affect individuals interested in interreligious study. Involved individuals are members of larger communities. We need to keep reminding ourselves that social patterns affect theologies, and even census data can play a part in a real and wellgrounded conversation.

Conversations across religious boundaries, including the scholarly HinduChristian conversations exemplified in this journal, must be placed within a frame where we keep noticing the dynamics of change occurring around us. Just as 100 years ago one could hardly discuss religious ideas comparatively without noticing the encompassing dynamics of colonialism, so too now, the demographics of each area of the world and the global scene itself must be noticed. Religions are not, and never were, timeless, and cannot speak merely from and of timeless essences. Those of us in either tradition, and those of us who study one or both, are therefore challenged to locate our reflection in the context of the changing world scene, wherein our work is either helpful, or irrelevant and missing the point as to where people are today, or even harmful, in the sense of distracting attention from the issues "on the ground" that matter to individuals and communities inside and outside India.

In the end, Religious Demography is a worried and somewhat gloomy book; surprisingly, a more theological perspective might have led to a more optimistic one. Christians have found, even in the West, that the increasing presence of people of other religious traditions invites and even encourages learning with and from the other. If other traditions are clearly going to be present in India and not to fade away, even after the possibility of military and economic enforcement of conversions is ruled out, then the new demographics will prompt a new and in theory unending conversation of Hindus with more, and more varied, non-Hindu neighbors. Add to this the increasing interaction of Hindus and nonHindus in the West, and we can see that the Hindu and Christian modes of dealing with others may be changing in a fundamental 
fashion, as we lose count of who belongs in which place.

It would be an interesting thought experiment to imagine the future - let's say, 100 years from now, or 200 - and ask how it might matter for Hindu-Christian relations were the demographics to shift even more radically. If Christianity was about to disappear from India, how might Hindus react? Some might not react at all. Jews are not foreigners in this book, but as their numbers wane to almost nothing in India, there seems to be no outcry from Hindus (including the authors) about the loss of these venerable Indian religionists. One wonders whether the authors might not react in the same way to the disappearance of the old Christian communities of south India. Similarly, were Hindu traditions to become, for instance, a minority in India itself, should the Christian interest in interreligious exchange decline? I hope not. Would sympathetic Christians help explain, defend, and revitalize Hindu traditions, as if preserving an endangered species? I hope so.

Yet all such possible or probable demographic changes can only count as factors in how religious groups make their decisions about how to understand and relate to one another; there are no merely set, merely static religious groups, and are no enduring conversations among believers who imagine their selves and the selves of others to be entirely, unchangingly settled. If we learn anything in dialogue, we learn to need one another, religiously. If so, it might also become a religious task to keep alive the diversity of the traditions that so characterize both India and North America: to keep counting, not out of fear or triumph, but out of joy at who we are becoming. I for one therefore hope for a companion volume from our authors, an imaginative (re)construction of Hindu identity that goes beyond the necessary groundwork of this valuable but incomplete volume. 